\title{
Application of Mixed College English Teaching Model Based on SPOC
}

\author{
Zhigang Lian \\ Heilongjiang Technology College, Jixi
}

Keywords: SPOC; mixed teaching model; college English; application

\begin{abstract}
With the rapid development of the curriculum, SPOC emerges as the times in order to meet the needs of individual primary schools, and has been widely used in the process of college English teaching. This paper constructs a mixed teaching model of college English online and offline combination based on teaching theory, analyzes the integration process of SPOC and college English, and designs the SPOC online learning resources, and flipped classroom activities in order to form the curriculum evaluation system, construct the mixed teaching model which can improve college students' English practical application ability.
\end{abstract}

\section{Theoretical Analysis on the Construction of Mixed College English Teaching Model Based on SPOC}

The theoretical basis of SPOC hybrid college English teaching model is the hybrid learning theory, which mainly refers to the mixture of cognitive and constructivism teaching theories, which is a virtual classroom of multimedia text, collaborative learning and a mixture of multi-media teaching and face-to-face teaching. Hybrid learning first appeared in 1999. At the beginning, people did not regulate it uniformly. With the rapid development of modern information technology, the definition of hybrid learning is constantly changing. In 2006 Professor Bonk and Graham defined hybrid learning as a mixture of face-to-face teaching and computer-assisted online learning. While the professor who first defined hybrid learning in China thinks that hybrid learning combines the advantages of traditional learning and modern digital learning. At the same time, Professor Huang Ronghuai believes that hybrid learning should be carried out in a virtual learning environment, providing learners with online resources through computer systems to ensure online communication between teachers and students. According to the definition of hybrid learning at home and abroad, hybrid learning mainly refers to the strategies and methods of teaching with different learning theories, different technologies and different application methods. It effectively exerts the advantage of online and offline learning and can ensure that students are more active in learning.

\section{Significance of Establishing Mixed Teaching Model Based on SPOC Platform}

The hybrid English teaching model based on SPOC platform can help teachers to understand the students' learning situation comprehensively, so as to carry on the teaching pertinently, and this teaching mode can also promote the students to learn actively and participate in the practice process actively.

On the one hand, from the teacher's point of view, the teacher can understand the problems of students during English learning through the results of the test and the questions asked by the students after watching the video, then design the teaching plan to improve the teaching efficiency. At the same time, the teacher can also have enough time to prepare the students' questions and give them satisfactory solutions, and the students will learn more knowledge and experience, so as to enhance their learning enthusiasm and finally form a virtuous circle. Therefore, the mixed teaching mode can help teachers make better use of their time in class and help students solve more learning problems, and teachers can improve their teaching level through more feedback information. However, this teaching mode requires high teaching level, so teachers will face great pressure of teaching, need to devote more energy and time to solve doubts and puzzles, and carefully check the feedback information of students. On the other hand, from a student's point of view, students should 
study the course video before class and complete the relevant tests to fully understand the content of the course to be learned. In this way, it is easier for students to keep up with the progress of teaching in class, and they are more willing to make more efforts for students. They can interact deeply with other students in class, thus enhancing the enthusiasm of students to participate in classroom learning and improving them English expression and group cooperation ability.

\section{Construction of Mixed College English Teaching Based on SPOC}

\subsection{Design micro courses that combine online micro video, micro exercises and micro resources}

SPOC online learning, online and offline tutoring and instant course evaluation are the main contents of online learning in SPOC mixed English teaching mode. SPOC online learning content mainly includes micro-course video, knowledge development and practice test and so on. According to the students' learning situation, college English teachers targeted choose the traditional classroom teaching content, and record it into a prominent focus, clear content and short micro-lesson video. It includes not only the explanation of English language knowledge and skills, but also the introduction of English culture and literary literacy. When designing language knowledge, teachers should choose the content of topic unit, which includes topic background, key words explanation, difficult analysis and communication skills, and students must learn deeply in order to lay a solid foundation for the subsequent reversal of the language output in the classroom. In the process of learning language skills, teachers should teach students several language skills, such as listening, speaking, reading, writing and so on, and complete the corresponding exercises, such as explaining pronunciation and intonation, so that students can look for keywords in listening. And master more precision and writing skills, but this part is optional, students can be completed in stages according to their actual learning conditions. The courseware resource is not simply to change the paper teaching material into the electronic version, but the teacher carefully selects the important and difficult content in the teaching material, sets up the multi-dimensional language situation, and presents it to the students by the way of PPT. And it also includes excellent works display and topic English soundtrack video and so on. The exercise test includes English knowledge point practice, language skill practice and so on. It can be divided into subjective exercise and objective exercise, which can effectively detect the effect of students' video learning in micro-class. The extension of video and extracurricular learning is the extension of knowledge, which is mainly an important material that requires students to learn deeply after completing their English topic study, and this material includes watching video and reading text, etc. During the period, students watch 2 to 3 videos and read 5 to 10 articles. They summarize and analyze the main points of view presented in the articles and videos, and express their views in the classroom discussions, and continue to consolidate their language skills through extended learning after class in order to effectively cultivate students' critical and creative thinking.

In the process of SPOC learning, students should complete the learning content independently, and the mixed teaching mode should provide students with many kinds of guidance methods. There are two kinds of tutoring modes: online and offline. The midline tutoring mainly refers to teachers using WeChat platform to set up WeChat group, including teachers, teaching assistants and students. In this group, teachers and assistants can answer questions that students ask online at any time. And carries on the on-line discussion, which has provided many kinds of solution methods for the student. The online discussion has realized the movement and extensive learning of English. The traditional physical classroom was replaced by the virtual mobile classroom, while the offline tutoring is that teachers regularly arrange quizzes for the class each month. Teachers face-to-face explain the English problems encountered by students during SPOC study and the completion of practice tasks. Before tutoring, students need to make an appointment with the teacher, and the teacher reasonably allocates the tutoring time according to the number of students appointed. Online discussion can effectively solve the common problems of all students and can be effectively solved by simple words. On the other hand, offline tutoring solves the problem of individual students. 
In the process of SPOC online learning, teachers should not only actively tutor students, but also record the students' learning process accurately, conduct supervision and inspection, and give objective evaluation to students' autonomous learning behavior. The SPOC field learning supervision and evaluation system is divided into two parts: objective and subjective parts. Learning platform can accurately record and count students ' learning time and academic achievement, and teachers analyze and evaluate the translation exercise subjects submitted by students and understand the actual learning effect of students. From this, we can see that the SPOC online autonomous learning mainly uses the methods of course guidance, micro-lesson video and feedback evaluation to complete the input task of English knowledge, which provides the basis for the mixed teaching of college English. It also provides the basis for the implementation of the above-line cooperative learning and micro-classroom teaching model.

\subsection{Design micro classroom teaching activities with the combination of line Display, discussion and debate}

On-line micro-courses are mainly completed by students on the basis of reasonable arrangement of their study time and schedule, while offline micro-classroom is divided into groups by teachers, and the learning results are analyzed and discussed through the cooperation between groups. The premise of College English teachers' flipped classroom teaching is online learning content, which is different from the past classroom mode. The micro classroom focuses divert from whether teachers transfer knowledge to students to whether they fully grasp knowledge and use it independently. In order to improve the efficiency of college English teaching, the number of offline microclass students in the class should not be more than 40, and the number of students in the group should not exceed 4. In the off-line micro-classroom, the teacher mainly takes the learning task as the driving factor, asks the student to study in cooperation, and the teacher instructs the student to report the study result, then the teacher and the student jointly carries on the appraisal.

For the lower grade students or the students with weak English learning ability, teachers should ask them to complete tasks with less difficulty, or to show them in class. During the class presentation, the teaching task should be from easy to difficult, from the study of introductory text to the expression of speculative views, and the students' reading and writing abilities should be strengthened in the process of summarizing the materials, and the students' oral communication level should be improved. In the presentation, teachers not only explain knowledge to students, but also coach and evaluate the effect of students' classroom presentation. In this teaching mode, students belong to the main body of learning, teachers only have the function of guidance and give objective evaluation, and they need students to share their views and strengthen cooperation before class, which also improves the students' ability of cooperative learning and language organization.

As students improve their learning ability, the task of offline learning should also be more difficult to design, such as displaying discussion and debate activities. Determine the topics of discussion based on SPOC's online learning content, and prepare the materials that students need during the debate, in order to form their owns' point of view, then use logical relation to carry on argumentation. In the process of discussion and dialectics, teachers can make evaluation to the individual and group according to the students' English expression effect and participation. In the discussion, students can internalize and practice the English knowledge they have learned, and solve problems through analysis and cooperation, and exchange different views with each other. The intercommunication in this process can provide a real environment for students to communicate in English. The formation of views will also help students to think critically, thus enhancing the output and application of language.

The key to construct a hybrid college English teaching model which is based on SPOC is to design autonomous learning activities, in which classroom activities are mainly based on online learning content and belong to the process of consolidation and reinforcement. The driving factor in the activity is to complete the project task and cultivate the students' consciousness of exploration and innovation. Under this teaching mode, the teacher has the function of tutoring and leading. Under the guidance of the teacher, the students can complete the process of input and output of 
English independently or in a cooperative way. However, if the whole learning process only depends on the students' self-control and learning interest, it is impossible to achieve the ideal effect. At this time, a complete learning supervision mechanism and a curriculum assessment mechanism should be provided to ensure the implementation of the mixed teaching model.

\section{Constructing the curriculum assessment system of formative and incentive evaluation}

In the process of mixed teaching, the assessment and evaluation of curriculum is a key link, which can ensure the completion of teaching content and teaching aim. The mixed college English teaching model based on SPOC can be divided into two kinds of learning methods, online and offline, as well as a variety of learning processes. Therefore, teachers should establish a diversified assessment mechanism based on the formative evaluation system and the incentive evaluation system, so as to build a multi-dimensional evaluation system for students to self-evaluate and achieve mutual evaluation of students and students. Formative evaluation pays more attention to the learning process of students and mainly evaluates the effect of stage learning, which is different from the previous evaluation system based on achievement. Formative evaluation is mainly divided into online and offline models. The method of teacher evaluation and student evaluation is used to investigate the learning process and learning effect of students. During the mixed teaching, students need to devote more time and energy to learning English knowledge, which will lead to the students with poor English scores to fear difficulties. In order to stimulate students' interest in learning, teachers should also set up an incentive evaluation system.

On-line evaluation mainly evaluates students' learning time and times on SPOC platform and students' learning effect according to unit exercises and test results. Offline evaluation includes classroom presentation, classroom participation and after-class reflection. And the evaluation involves listening, speaking, reading, writing and other English skills. The teaching content is divided into four topics, and each topic has periodic examination content. At the beginning of the school year, the students have not fully entered the study state, the results of the first topic are only 20 percent, and the middle topic scores are 30 percent. At the end of the semester, the students have to face multi-disciplinary examinations, and they cannot concentrate all their energy on the English learning process. Therefore, the final stage of the topic scores accounted for 20 percent. At the same time, it should be divided into topics online learning time, online practice time and offline task and so on, and the offline evaluation is divided into teacher evaluation, student self-evaluation, student mutual evaluation and group evaluation, etc. The evaluation is mainly based on group members' participation, teamwork awareness, content organization, persuasiveness and language expression ability. In order to encourage the students to face the learning content actively and urge them to complete the learning results better, the score of each learning incentive evaluation is $5 \%$.

The effective combination of formative evaluation and incentive evaluation system can ensure students to invest more energy in English learning, but also can objectively reflect the degree of effort and learning effect of students, and indirectly enhance students' interest in learning English.

\section{Conclusion}

The hybrid teaching model based on SPOC platform mainly utilizes classroom teaching mode and modern information technology, which can help college English teachers to carry out targeted teaching and ensure students' active participation in the teaching process. Improve students' English proficiency.

\section{References}

[1] Zhang Yi, Gao Li. Applied research on mixed teaching mode of college English: a school-based study [J]. Chinese Educational Informatization. 2015(09)

[2] From MOOCs to SPOCs[J] . Armando Fox. Communications of the ACM. 2013 
[3] Constructivism in Practice: Designing, Thinking and Learning in a Digital World. Kafai, Y, \& Resnik, M. 1996

[4] The flipped classroom strategy: What is it and how can it best be used. Milman N B. Distance Learning. 2012

[5] How "Flipping" the Classroom Can Improve the Traditional Lecture. Berrett, Dan. The Education Digest. 2012 